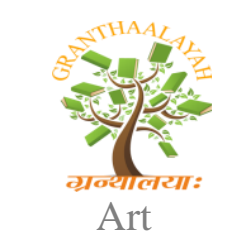

INTERNATIONAL JOURNAL Of

RESEARCH -GRANTHAALAYAH

A knowledge Repository

Art

\title{
IMPORTANCE OF COLOURS IN INDIAN ARTS
}

\section{Dr. Suchitra Harmalkar}

Life is a pallet of colours; every colour has its own importance. Imagining a life without colours is not possible. Psychologists say that colours are a direct reflection of a person's life and personality. The kind of colours he chooses says a lot about his mood, traits and nature.

Hence Colours can be called a nonverbal form of communication. Colours have energy that can define as well as change the moods and actions of any person. Indian culture is said to be an amalgamation of various colours. Every colour holds a special place in India. Colours play a vital role in the day to day life; in India a simple colourful dot in the centre of the forehead of a woman denotes her colourful life, the presence of a healthy marriage. While an orange colour dot on the forehead of a person connotes that he is devoted to god or was in prayer. This is how a little colour adds a lot of meaning on the bigger picture of life. A single colour has a potential to announce or reveal athousand words at a single time.

Since colours in it are very expressive hence they also form an important part of all performing arts specifically the visual arts, be it dance, painting, crafts, theatre, designing or music. Theatre is a collaborative form of fine art that uses live performance to represent any real or imagined script. Since theatre is a complex art that involves a broader and wider perspective of a story, colours have played a major role be it make up, costumes or sets. To bring a story live, it is important to create an ambience similar to the actual scene so that the audience can visualize and connect to the script. Setting the backdrop in plain blue is enough to let the audience experience a flowing river. Theatre has grown a lot in the last few years. Contemporary theatre focuses more on symbolization. A single colour is able to advertise a lot of contrast emotions. A basic colour as red at one hand signifies romance, love, compassion while at the other hand signifies anger or destruction. In Chinese theatre, red is used to symbolize luck and fertility while the Aztecs depict status and strength using red on screen. The modern form of theatre popular in the present scenario is the movies. A drastic change in the presentation of colours can be seen through this art. The famous director Mr Sanjay LeelaBhansali is known to be a man of colours who combines a lot of colours by using costumes, sets, make up, jewellery and other aesthetics as a medium to create a vibrant scenario on the big picture. Not only theatre, the beauty of colours also extends to the various other forms of art, also to those which do not have a visual component in it at a larger side. One of which is vocals and music. Human psychology relating to colours is very interesting, and also differs from person to person. But a common perspective is that every person can paint an image or relate to something specific by merely listening to the name of the colour. For example as soon as one person hears green, the first thing that might pop in his or her head is plants, greenery etc. this is how this human psychology is used by the singers and lyricists to create an impact on the audiences through their songs. Songs like "ye laal rang mujhekabchodega", "neele neele ambar par, chand jab aaye", "humpe ye kisnehara rang daala" are examples of songs that create or symbolizes situations through the medium of colours because colours have proved to be the easiest way to strike minds of the listeners.

Unlike vocals and music, dance is an observable form of art, than can be seen and perceived by the audiences which undoubtedly increase its scope. Considering here the importance of colours 
in Indian dance forms is wide and vivid in nature. It is unimaginable to think of an Indian folk dance without its colourful regional costume and props. Indian folk dances, all of them are a depiction of the happy moods of the tribe, hence vibrant coloured costumes and ornaments are worn by the people while performing these dances. Certain colours in costumes also illustrate the features of a particular folk. For example kalbelia folk dance of rajasthan is performed by wearing black colour lehenga and choli with silver lining and colourful thread work on it with heavy and colourful metallic jewellery, the black colour here represents that the kalbelia tribe performing the dance is related to snake charmers. Here the colour becomes the identity of a folk. Similarly while performing gidda folk dance of Punjab or lavani of Maharashtra; women adorn bright coloured costumes to connote certain celebration or joy. Not only do the folk dances but also the classical dances of India adopt colours to show a variety of things. In a kathakali dance of south India, make up involves a lot of colour which is a distinct feature of this dance. When a positive character has to be depicted, the face of the dancer is painted green and his eyes and lips are enhanced by using different colours such as red and white while if a negative character has to be shown, the face of the dancer is painted red. Symbolization is possible becauseof these colours used in makeup. The significance of colours in costumes, make up and sets in dance is unquestionable but it is also paramount in the content of kathak dance. A lot of things are shown with the help of colours. Such as Krishna is shown by depicting black kohl in eyes, or the back of the palm of the hand as it is a common belief that Krishna was dark in complexion, similarly fair radha is shown by comparing her with the purity and whiteness of the moon or sparkling colours of the stars. Words like "bhaado nisi andhiyaari, chchaayighanghatakaari" here the word kaari which means black is sufficient to describe the dark and lonely road at night. In the same way, shyamvarna, peetvastra which means black complexion and yellow clothes complete a beautiful image of lord Krishna. This is how colours add essence to the world of dance.

Designing and architecture is the most important art form when usage of colours is considered. Colours are an integral part of this art. Different permutations and combinations of colours are worked out to give a soothing effect to the masterpiece. Every colour calls out different styles of living. Certain people prefer vibrant, spirited and energetic colours while some prefer colours which are dull and reserved. But the thing to be noted is that each colour has its own beauty, if it had not been true then a historical monument of sole white colour would not have been a wonder of the world. Research has proved that the colours you are surrounded with directly affect your life. In an experiment conducted in Pennsylvania, USA, it was seen that two persons suffering from the same disease were kept in two different rooms and given the same treatment; the difference was that one of them was kept in a room with walls painted with striking and bright colours while the other was kept in a room with dull colours. It was later observed that the person in the first room responded to the treatment in a better and positive way than the other. This experiment proved that designing and architecture are largely dependent on the variety of colours. Therefore subjects relating to colours are also an integral part of architectural studies.

Colours are a gift of god, it is a silent art of communicating, and it is a language used to convey a variety of unsaid emotions. A new born child who is unable to understand the meaning of words, smiles seeing a colourful toy, nothing than this can be a bigger example to show the influence of colours on our lives. Colours are a pronouncement of all the emotions of life combined together. As quoted by Ernst Haas, "colour is joy, one does not think joy, one is carried by it." 